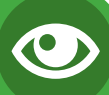

\title{
El papel esencial y discreto de la filosofía
}

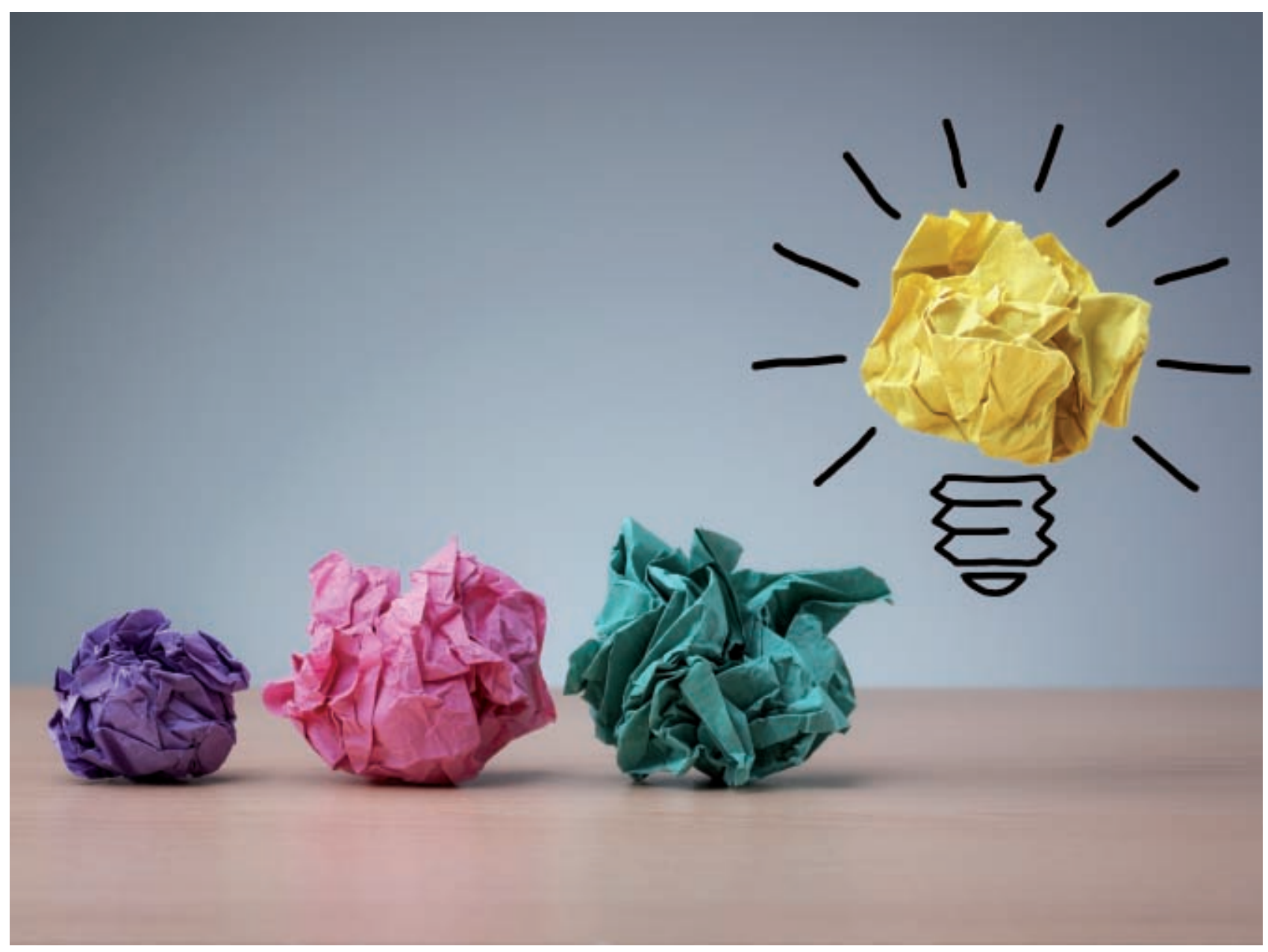

La formación de las personas es el tema en el que más imaginación, experiencia, ideales y buena voluntad debe ponerse. Que muchos ensayos de realizarla no hayan sido felices no puede evitarnos seguir pensando cómo son las verdaderas condiciones perfectas para dar ocasión a que la humanidad del futuro supere con mucho a la humanidad del presente.

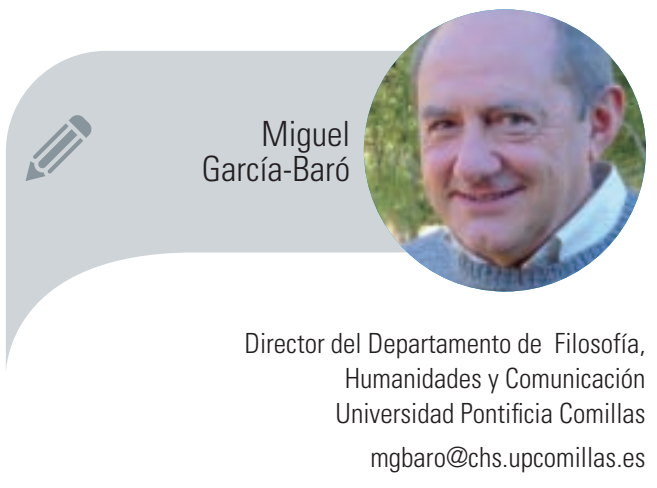


La palabra filosofía puede asustar: tiene algo de solemne, de antiguo, de referencia a erudición y hasta a ratones de biblioteca. No sé si es la más útil para animar a padres, educadores y niños en el sentido que considero necesario (y no habrá que decir que animar a los padres y a los educadores es mucho más complicado y más urgente que animar a los chicos). Por otra parte, no podemos dejar a un lado que la enseñanza de la Filosofía ha sido en muchos casos muy perniciosa para su subsistencia en el sistema educativo. Todos los profesores de ella en la universidad nos hemos encontrado multitud de personas vacunadas contra la permanencia de la filosofía en el Bachillerato (si no incluso como licenciatura o grado independiente) por sus primeros instructores en la materia. Y cuando no ha sucedido esta catástrofe (puesto que lo que quiere decir filosofía se verá después hasta qué punto es deseable en cualquier horizonte siquiera una pizca utópico de la enseñanza media), ihay que ver, sin embargo, qué cosas se han trasmitido bajo, por máximo ejemplo, el nombre de Platón a los sufridísimos oyentes! Y es que precisamente la Filosofía no se deja simplificar; de modo que intentar un gran curso de su historia entera en el Bachillerato es arriesgarse a dejarla en una lista de nombres de abigarradas relaciones cronológicas entre ellos, más una serie inconexa de afirmaciones bastante enloquecidas. Al final, sin un relato coherente y sin un fundamento firme, la Filosofía parece en este caso una colección de paradojas orientadas a poner patas arriba la vida tal como realmente es a diario y enfrentada a sus enigmas y sus problemas reales. El alumno no la ha odiado, pero se ha quedado estupefacto y al margen.

El asunto no está en enseñar filosofía sino, precisamente en las primeras edades, en enseñar a filosofar sin pronunciar semejante palabro.

¿Qué es lo que aporta este filosofar que no se nombrará?

Un niño, un chico necesita de la escuela (entiéndase este nombre en el noble sentido amplio que tiene tradicionalmente) nueve cosas esenciales: aprender a leer,

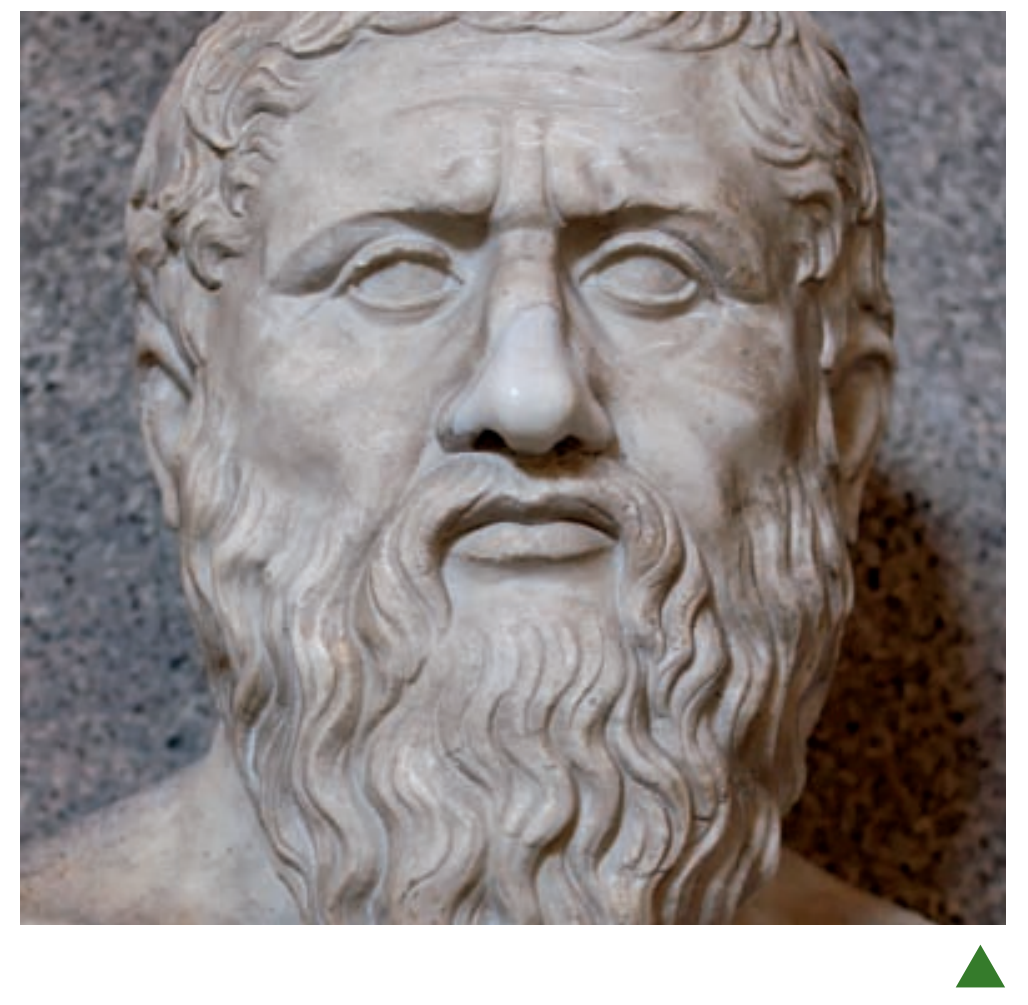

aprender a escribir, aprender a pensar, aprender a sentir con hondura, aprender las bases de los saberes, aprender las bases de las técnicas, iniciarse en un arte, aprender sentido histórico, aprender convivencia y aprender los fundamentos de la vida política. Tiene que traer de su casa los rudimentos de las virtudes morales y de la buena educación; tiene que exigir de sus maestros estas nueve cosas, estas nueve virtudes intelectuales, sobre las que él mismo tendrá que edificar su prudencia y orientar su vida. Naturalmente, es la familia la que, en nombre de su hijo o su hija, tiene que exigir todo esto de la escuela. Naturalmente, los educadores tendrían que estar perfectamente imbuidos de que su labor no se extiende a menos que a todo este formidable (pero estrictamente necesario) panorama; así que deben constituirse en equipo que mantenga lo ideal del programa conjunto de la escuela y que no se deje distraer de sus altísimos fines por ninguna especie de burocracia. Por favor: este deben es exactamente un deben de orden moral, que no sería superfluo que pasara a serlo también de orden contractual (y, por supuesto, vocacional y profesional); aunque una agencia de calidad, como ahora se dice tanto (tergiversando, por cierto, el sentido de la palabra "calidad" casi sistemáticamente), no puede hacer realmente ningún servicio si el equipo de maestros no está en armonía y no ha visto claro alguna vez
Busto de Platón. Wikimedia Commons [Public domain], via 


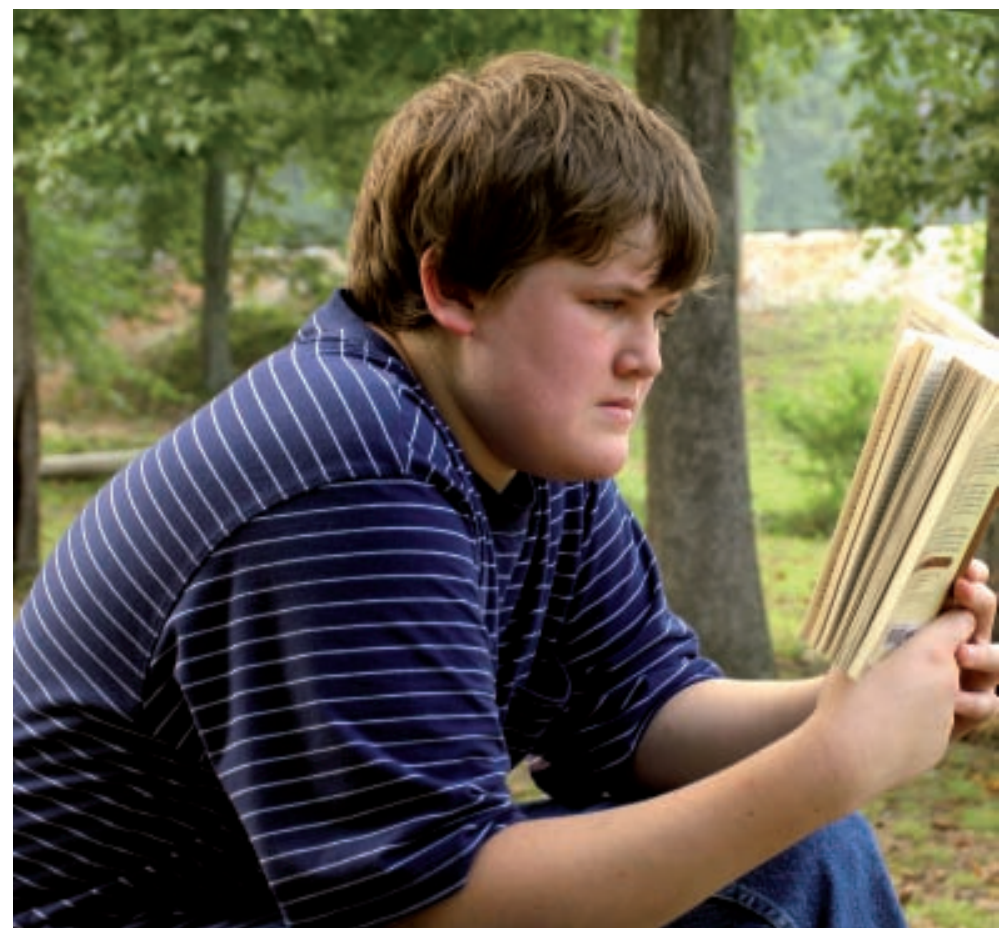

El asunto no está en enseñar filosofía sino,

precisamente en las primeras edades,

en enseñar a filosofar sin pronunciar

semejante palabro

a cuánto llega su responsabilidad. Lo demás es paternalismo tanto desagradable como inútil. Y una persona muy joven que detecta a su alrededor farsa, simulacro, pereza, mucho cubrir el expediente y poco entregarse al deber y a los educandos, nota inmediatamente la profunda violencia que late debajo de todo esto, por suave que se presente su superficie. Y si hay violencia real, latente o patente, la educación se volatiliza en el mismo momento y la escuela se convierte en una especie de campamento de castigo para todos los que están sometidos a vivir en ella.

Adrede no he querido enumerar competencias, valores, actitudes ni otras zarandajas del mismo estilo. Veamos por qué repasando someramente la lista de las obligaciones de la buena escuela.

Aprender a leer. A solas primero y, quizá, en grupo después, aprender a asimilar de alguna manera dentro de la propia vida las aportaciones de otras vidas de cualquier época y cualquier lugar. Aprendizaje de silencio, de concentración, de reflexión, de modesta pero real lectura de la propia situación en la vida. Y para esto no se necesita dar un libro de "filosofía" al educando. Al contrario, los relatos de ficción y las noticias del periódico deben ser el material básico aquí.

Aprender a escribir y aprender a pensar. Casi significan lo mismo estas dos cosas. Una vez que se va abriendo despacio la capacidad de recibir mensajes ajenos, que uno no había imaginado siquera, el complemento esencial de este recibir es reaccionar explícitamente (por supuesto, no hay que exigir que esta reacción delate factores muy íntimos de nadie; es inflnitamente más provechoso que los temas tengan una cierta objetividad, una distancia posible respecto de las circunstancias inmediatas de la escuela y la familia, aunque siempre guardando relación con estas circunstancias). Aprendiendo a expresarse por escrito con claridad, concentradamente, asimilando las infinitas posibilidades de la lengua materna, se aprende a la vez a pensar con orden, a pensar al mismo tiempo en muchas posibilidades que no se ofrecen como un caos.

El abandono del ejercicio de redactar en la escuela, y la sustitución del esfuerzo de leer por sucedáneos tristes (libritos arreglados en los que apenas entra la realidad por ninguna rendija, y mucho menos el tesoro de la lengua), inducen a la falta completa de pensamiento propio claro y ordenado. Y si un educando no se acostumbra a entrar en diálogo con la realidad, con las perspectivas ajenas sobre la realidad, con sus propias perspectivas simplemente asimiladas en la familia o con los amigos (de modo que de este diálogo vaya surgiendo una posición de veras personal y creída un poco en serio), estará dejando para otro momento el poner las bases del sentido de su libertad y su responsabilidad.

El papel de la filosofía en la escuela se concentra en este triple aprendizaje fun- 
damental: leer, escribir y pensar. Hay que ir subiendo poco a poco en generalidad, en importancia los temas sobre los que se lee, piensa y escribe. Si el comienzo está en las noticias y los relatos de ficción (pero no simplones y cursis, por Dios), enseguida entre las primeras surgirán los desafíos de la actualidad de muchas maneras; luego será fácil elevar también el grado de universalidad (de trascendentalidad, como se decía antiguamente) de los relatos que se empleen. Debería aquí recordarse a los enseñantes la estupenda cantidad de cuentos que hallarán en la literatura española casi de todas las épocas. Clarín, Aldecoa, Unamuno, Borges, Cortázar, Delibes, Matute, Cunqueiro, Rulfo, Benedetti, Lugones, García Márquez...; y, naturalmente, Chéjov, Tolstói, Poe, Balzac, la Biblia...

Una vez que se ha entrado en el mundo de la lectura y la escritura, los filósofos morales de todos los tiempos están al alcance. En nuestro caso, a través del Quijote es facilísimo leer la Defensa de Sócrates platónica; lo esencial de la llíada puede, a su vez, introducir en el teatro clásico (la Electra y la Antígona de Sófocles, el Filoctetes de Eurípides; para saltar desde aquí a Corneille, algo de Calderón, las tragedias históricas de Shakespeare (no digamos el valor que puede tener introducir en la escuela la discusión del Romeo y Julieta o del Macbeth), Schiller, Ibsen, Max Aub). ¿Suena utópico? Pues justamente de eso se trata, que llevamos demasiados años sin recrear utópicamente ni la escuela ni la universidad.

Y el teatro clásico cae ya dentro del aprender a sentir y del aprender las bases de algún arte. Por sí mismo, puede llevar también a otros textos filosóficos elementales: algunas cartas de Séneca, muchos extractos de Cicerón (aquí casi todo es instructivo y, además, pasa gradualmente y casi sin sentir de la ética al problema del conocimiento; pero siempre al principio estaría usar en este sentido los libros De finibus), fragmentos de los diálogos iniciales de san Agustín).

Pero es que la escuela debe introducir a la práctica del teatro, no sólo a su lectu-

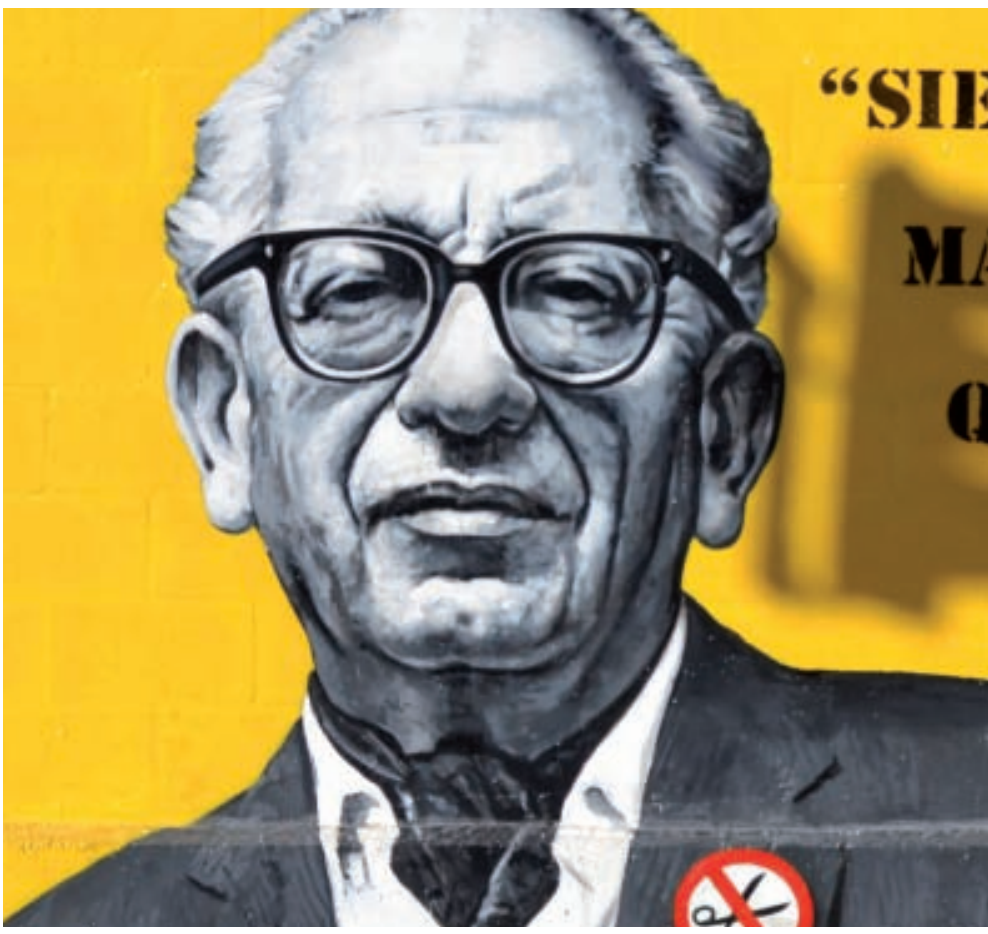

ra. Y esta práctica ¿no se acompañará con la introducción a la música, al dibujo, a la pintura, a la escultura? Todos los elementos que se reúnen en la representación teatral pueden practicarse en el aula. Si se ha escogido un drama de Chéjov, por ejemplo, para conseguir montarlo a lo largo de todo un curso, ¿cómo se dejaría a un lado el preparar los decorados y las posibles ilustraciones musicales?

Yo encuentro lamentabilísimo que apenas se pase jamás en la práctica educativa de ahora del simulacro (repito esta palabra terrible muy adrede, después de mi larga experiencia como padre) de soplar en una flauta de plástico, manchar una tela y hacer una función con bailes bastantes ridículos una vez al año. Allí no se ha leído poesía; no se ha educado el oído para la gran música; no se ha probado seriamente de ninguna manera la capacidad expresiva de los niños con la arcilla, los colores, el piano o el violín. Estas no son "actividades" fuera de horario, para pagadas aparte y agotar las jornadas de los chicos a la vez que se facilita el horario de sus padres. Son instrumentos educativos esenciales, que tampoco deben ser tan reglamentados desde la autoridad que no dejen amplio campo de inventiva a los equipos educativos de cada centro (siempre que haya realmente tales equipos o, al menos, la voluntad decidida de constituirlos).
Max Aub en un mural del colegio Max

Aub de Valencia. By Joanbanjo (Own work) [CC BY-SA 3.0 (http:// creativecommons.org/ licenses/by-sa/3.0)], via Wikimedia Commons. 


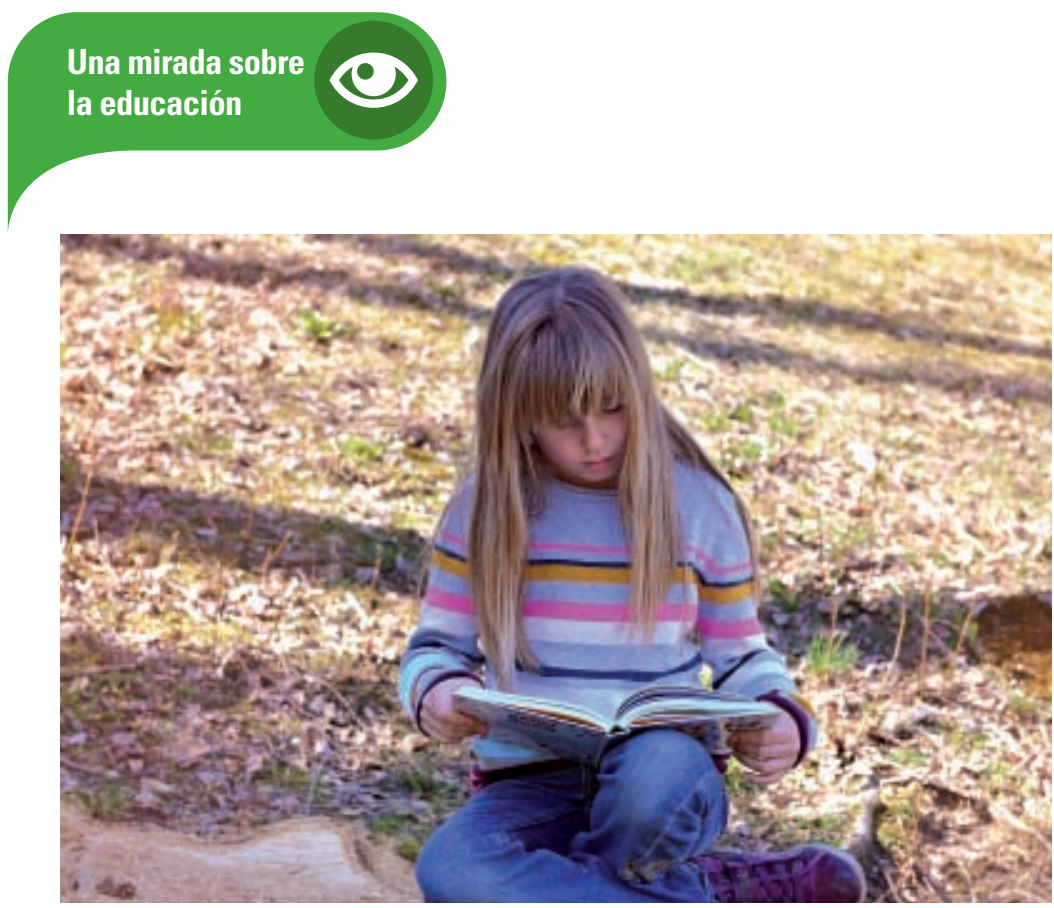

¿Por qué me atrevo a decir que son instrumentos educativos esenciales y por qué, cuando se me ha pedido que hable de la filosofía en la escuela parece que hablo de cualquier cosa menos de ella?

Llegamos aquí al punto esencial, desde el que luego revisaremos con más ligereza y más hondura las cinco exigencias de las que antes hablé y que aún no he comentado.

Este punto es que hay que dejar que la vida real entre en la escuela realmente, si se me permite decirlo así. Y en la vida real los chicos se enfrentan ya siempre a los misterios de la existencia. Los maestros no tienen que inculcárselos (lo que, además, es imposible: de eso se encarga la realidad misma, o sea, la divina providencia). El papel de la escuela no es ni distraer de los misterios de la vida ni, mucho menos aún, convertir a la persona joven en una útil pieza de la maquinaria en que tiende en todos los tiempos a convertirse la sociedad (defendida en esto por un Estado que paga para ella cantidades ingentes de dinero destinadas al sostenimiento de la escuela pública y semipública). El que comprende o simplemente barrunta que en el tiempo de la escuela se trata de una de estas cosas o de las dos al mismo tiempo, dejará la vida real en el perchero, junto con el abrigo y el desayuno (ésos sí son reales), y verá luego hasta qué punto le conviene dejarse entretener y dejarse convertir en pieza útil. Formarse quedará para la vuelta a la calle, "a la buena de Dios" (que es la blasfemia española por antonomasia). Y si la familia está también distraída o, sencillamente, está desestructurada, como solemos decir con una especie de eufemismo, será la empresa la que domestique brutalmente al chico la primera vez que lo emplee.

No hay para qué extenderse en la presencia de los misterios en la vida de los niños. Hay el misterio del amor familiar (o del desamor familiar), en primer término. La familia es el lugar capital tanto de la salud como de la enfermedad mental y social. Incluso cuando la familia no está aparentemente desestructurada, puede ejercer una influencia devastadora en el niño con su violencia, sus tensiones, su mismo (hoy frecuentísimo) cerrarse sobre sí misma. La felicidad o la infelicidad de la infancia llenan de misterio la vida ya para siempre; la dotan de una dimensión de profundidad que la escuela tiene que formar también, aunque con infinito cuidado (todo misterio se hace respetar, por definición). La infelicidad del niño lo hace entrar en el circuito repugnante del miedo, causa principal de la crueldad (malévola o ingenua). Un objetivo primordial de la educación es inculcar por todos los medios posibles en cada persona la certeza de que no se puede vivir con el corazón aterrorizado; de que cada uno es libre, responsable y, sobre todo, por ello mismo, capaz de levantar el edificio de la propia vida de mil maneras insospechadas, porque todo hombre, por desgraciada que sea la situación de la que parte, tiene en sí mismo los recursos para lograrlo.

¿Qué haría la escuela enseñando (más o menos) quién fue Descartes, pero no intentando remediar el miedo, no intentando dar un eficaz sentido de capacidad, de libertad, de entusiasmo para todo, al chico que entra tan desvalido en la vida? Que se eduque su sensibilidad para poder ir asimilando a solas el misterio de estar vivo, de ser amado o no amado, de tener que amar o no amar a quien se tiene junto a sí.

Aprender las bases de los saberes y de las técnicas. Aprenderlos de veras, demostrativamente en el caso de los saberes y bien manualmente en el caso de las técnicas. Nada aquí de paternalismo (en ninguna parte se debe dar cabida a esta plaga). Hay que seleccionar de manera ri- 
gurosísima a quienes se han de encargar luego de iluminar las cabezas y las manos con estas disciplinas. Es casi un crimen enseñar matemáticas o física sin auténtica demostración; lo es también introducir en las ciencias biológicas o la geografía (un saber de maravillosa generalidad, normalmente descuidadísimo en todos los sistemas educativos) sin orden ni concierto, con exceso de datos dispersos.

Demostrar, exponer los hechos y saber hacer. Esto es ya Ilenar realmente de recursos al joven. Es hacerle ver que las cosas se entienden y se dominan, y que entenderlas ordena al mismo tiempo en gran medida su propia vida misteriosa. $Y$ es intolerable que una persona termine la escuela sin ninguna habilidad manual y sin haber siquiera visto lo extraordinariamente atractivo que puede ser dedicarse a un oficio mecánico una vez que se cuenta con este suelo vital y cultural que debería proporcionar la escuela.

Y dentro de este capítulo de aprendizajes sitúo las bases de la educación física, el deporte, la dietética.

\section{Aprender sentido histórico, convi-} vencia y política. De hecho, la convivencia dentro de las aulas debería vigilarse, mejor dicho, formarse con máximo cuidado. Si ella es deficiente, la escuela deja automáticamente de cumplir todas sus funciones y abandona "a la buena de Dios" a sus alumnos. Igual que es inconcebible (pero frecuente, porque las cosas de la vida suelen ser inconcebibles) que termine alguien la escuela sin nociones de salud y dietética, e incluso de enfermería elemen-

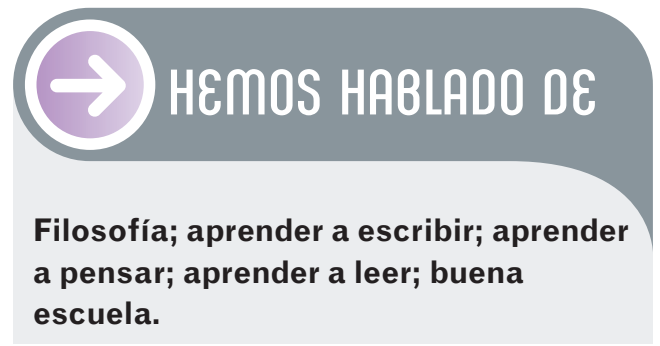

Este artículo fue solicitado por PADRES y MAESTROS en diciembre de 2014, revisado y aceptado en mayo de 2015.

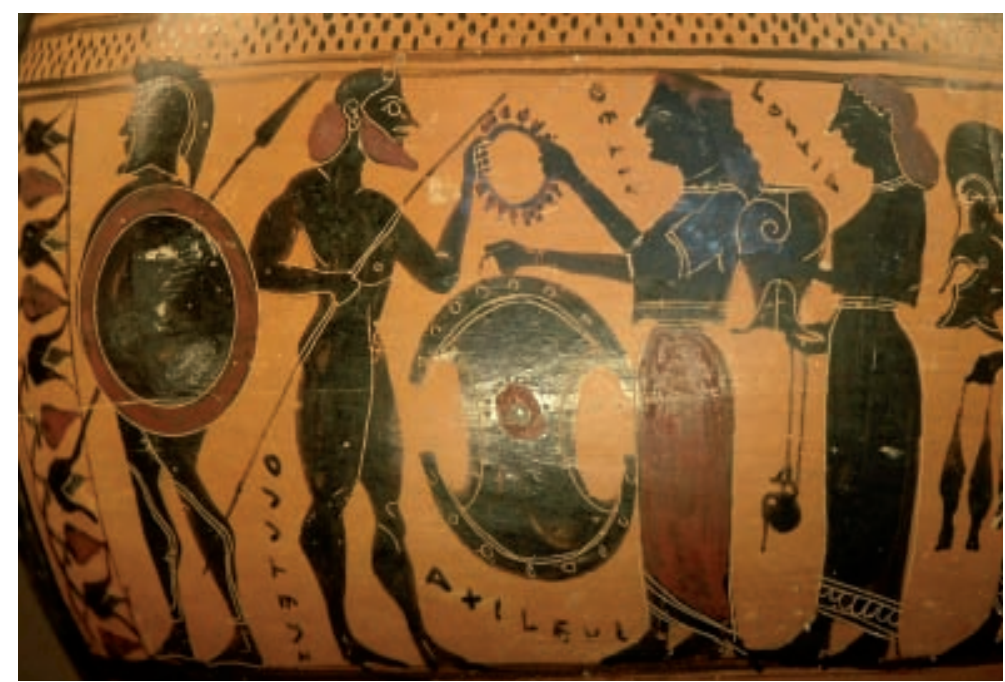

tal, es inconcebible (y más que frecuente) que se termine la educación esencial sin nociones de economía y derecho. Pero estas nociones pueden y deben aprenderse en la vida misma de la escuela; y por ellas solas reclamarán sentido histórico a los jóvenes. Logrado el interés por éste, todo lo necesario estará hecho. De la escuela saldrá un ciudadano libre y activo, con grave conciencia de lo misterioso y lo problemático de la vida, pero también de sus capacidades para renovarla; una persona Ilena de deseos de instruirse a fondo en algún saber o en alguna técnica; una persona que no podrá dejar el hábito de leer, de pensar, de escribir; una persona para la que la expresión artística no sea ajena. Y este ser humano que da así el paso hacia la universidad o la escuela profesional, ¿cómo no se interesará por los pensamientos más profundos que el pasado y el presente le ofrecen acerca del bien perfecto y de la verdad? ¿Cómo carecerá de sentido para lo religioso? ¿Cómo no habrá educado su corazón para sentir repugnancia ante el odio y la mera fuerza bruta?

Esto no son imaginaciones sino profecías, puesto que estas cosas las necesita el mundo más que seguir dando vueltas alrededor del Sol •

\section{DAR DRR SABER MÂS}

Gorgias (trad. y comentario del diálogo platónico, Miguel García-Baró) (2010). Salamanca: Sígueme.

García-BAró, M. La filosofia com a dissabte. Barcelona: Editorial CruïIla.
Tetis entrega a Aquiles la armadura fabricada por Hefesto. Marie-Lan Nguyen / Wikimedia Commons (Public Domain) 